\title{
Quantification of the individual risk of each Gleason pattern, including tertiary Gleason pattern 5, after radical prostatectomy: development of the modified Gleason grade grouping (mGGG) model
}

Satoru Taguchi ${ }^{1,2^{*}+} \mathbb{D}$, Yukari Uemura ${ }^{3,4 \dagger}$, Tetsuya Fujimura ${ }^{5}$, Teppei Morikawa ${ }^{6}$, Akihiro Naito ${ }^{2}$, Taketo Kawai ${ }^{2}$, Motofumi Suzuki ${ }^{2}$, Haruki Kume ${ }^{2}$ and Hiroshi Fukuhara ${ }^{1}$

\begin{abstract}
Background: While the new Gleason grade grouping (GGG), which started in 2016, has been widely validated in prostate cancer, it does not incorporate the concept of tertiary Gleason pattern 5. Furthermore, no study has "quantified" the individual risk of each Gleason pattern, including tertiary Gleason pattern 5, after radical prostatectomy.
\end{abstract}

Methods: We reviewed 1022 men with adjuvant-treatment-naïve prostate cancer who underwent radical prostatectomy between 2005 and 2017. The primary endpoint was biochemical recurrence-free survival, defined as two consecutive prostate-specific antigen measurements $\geq 0.2 \mathrm{ng} / \mathrm{ml}$ after surgery. The individual quantitative risk score (IQRS) of each amount (primary/secondary/tertiary) of each Gleason pattern (3/4/5) was calculated using the Cox regression model. On the basis of the IQRS, the modified Gleason grade grouping (mGGG) model was developed. As a robustness analysis of the MGGG model, salvage treatment-free survival was also assessed.

\footnotetext{
*Correspondence: satorutaguchi33@gmail.com

†Satoru Taguchi and Yukari Uemura contributed equally to this work. 'Department of Urology, Kyorin University School of Medicine, 6-20-2 Shinkawa, Mitaka, Tokyo 181-8611, Japan

${ }^{2}$ Department of Urology, Graduate School of Medicine, The University of Tokyo, 7-3-1 Hongo, Bunkyo-ku, Tokyo 113-8655, Japan

Full list of author information is available at the end of the article
}

(c) The Author(s). 2020 Open Access This article is licensed under a Creative Commons Attribution 4.0 International License, which permits use, sharing, adaptation, distribution and reproduction in any medium or format, as long as you give appropriate credit to the original author(s) and the source, provide a link to the Creative Commons licence, and indicate if changes were made. The images or other third party material in this article are included in the article's Creative Commons licence, unless indicated otherwise in a credit line to the material. If material is not included in the article's Creative Commons licence and your intended use is not permitted by statutory regulation or exceeds the permitted use, you will need to obtain permission directly from the copyright holder. To view a copy of this licence, visit http://creativecommons.org/licenses/by/4.0/ The Creative Commons Public Domain Dedication waiver (http://creativecommons.org/publicdomain/zero/1.0/) applies to the data made available in this article, unless otherwise stated in a credit line to the data. 
(Continued from previous page)

Results: During a median follow-up of 45 months, 229 of 1022 (22.4\%) patients developed biochemical recurrence. The IQRS of each Gleason pattern was as follows: primary 5, 1.81 points (hazard ratio [HR] 6.13); secondary 5, 1.37 points (HR 3.92); tertiary 5, 0.87 points (HR 2.39); primary 4, 1.07 points (HR 2.91); secondary 4, 0.79 points (HR 2.21); and any Gleason pattern 3, 0 points (HR 1). Based on the IQRS, the mGGG model was developed, which classified patients into the following five groups: I $(3+3$ or less); II $(3+4)$; III $(4+3)$; IV $(3+4+t 5,4+3+t 5,3+5,5+3$, and $4+4) ; V(4+4+t 5,4+5,5+4$, and $5+5)$. The $c$-index for biochemical recurrence-free survival was significantly improved from 0.655 of the original GGG model to 0.672 of the $\mathrm{mGGG}$ model $(P<0.05)$. In the robustness analysis, the c-index for salvage treatment-free survival was also significantly improved from 0.619 of the original GGG model to 0.638 of the mGGG model $(P<0.05)$.

Conclusions: The quantitative risk of tertiary $(<5 \%)$ Gleason pattern 5 is slightly higher than that of secondary $(5-$ 50\%) Gleason pattern 4. Our newly developed mGGG model more accurately predicts outcomes after radical prostatectomy than the original GGG model.

Keywords: Gleason grade grouping, Gleason score, Prognostic model, Prostate cancer, Prostatectomy, Quantification,

\section{Background}

Since the Gleason scoring system for pathological diagnosis of prostate cancer (PC) was published in 1966 [1], it has been widely used in clinical practice and has evolved over time. The concept of tertiary $(<5 \%)$ Gleason pattern 5 [2] has been implemented since the 2005 International Society of Urological Pathology (ISUP) Consensus Conference on Gleason Grading of Prostatic Carcinoma [3]. The prognostic significance of tertiary Gleason pattern 5 has been widely validated in various settings of PC [4-16]. In 2016, the new Gleason grade grouping (GGG) [17] started to be used in clinical practice, according to the 2014 ISUP Consensus Conference on Gleason Grading of Prostatic Carcinoma [18]. Although the prognostic value of GGG has been confirmed in several settings [19-21], it does not incorporate the concept of tertiary Gleason pattern 5. A recent study reported that integrating tertiary Gleason pattern 5 into GGG improved the accuracy of predicting the patient's outcome after radical prostatectomy [16]. However, no study has assessed the actual effect of tertiary Gleason pattern 5 on outcomes of patients with PC. Therefore, the present study aimed to quantify the risk of each Gleason pattern, including tertiary Gleason pattern 5, after radical prostatectomy and to develop the modified Gleason grade grouping (mGGG) model.

\section{Methods}

The internal institutional review board of the Graduate School of Medicine and Faculty of Medicine, The University of Tokyo approved this retrospective study (approval number: 3124). We reviewed 1167 patients with PC who underwent radical prostatectomy at The University of Tokyo Hospital between 2005 and 2017. We excluded 32 patients who had received neoadjuvant androgen deprivation therapy (ADT) to guarantee an accurate pathological diagnosis. We also excluded 113 patients who received adjuvant treatment after surgery (radiotherapy, $n=14$; ADT, $n=64$; and both, $n=35$ ) to assess the pure oncological outcome of surgery alone. Eventually, 1022 adjuvanttreatment-naïve patients were available for analysis (Fig. 1). All prostatectomy specimens were pathologically reviewed according to the 2005 ISUP Consensus Conference on Gleason Grading of Prostatic Carcinoma [3].

The primary endpoint was biochemical recurrencefree survival (BRFS), defined as two consecutive prostate-specific antigen (PSA) measurements $\geq 0.2 \mathrm{ng} /$ $\mathrm{ml}$ after surgery [22]. Salvage radiotherapy and/or ADT was implemented when biochemical and/or radiological recurrence was observed [22-25]. We used KaplanMeier analysis with the log-rank test to determine survival differences among categories. Univariate and multivariate Cox proportional hazards regression models were also used to predict outcomes. Follow-up information was obtained as of March 2018.

The individual quantitative risk score (IQRS, points) of each amount (primary/secondary/tertiary) of each Gleason pattern (3/4/5) was calculated using the Cox regression model, and reported with the corresponding hazard ratio (HR). The HR was calculated from the IQRS by the following formula: $\mathrm{HR}=e^{\mathrm{IQRS}}$. The IQRS of any Gleason pattern 3 was set as 0 points (HR 1), because a Gleason score (GS) of $3+3$ rarely correlates with PC-specific death and metastasis, despite being pathologically malignant $[26,27]$. On the basis of the IQRS, the mGGG model was finally developed. Concordance (c) indices were calculated both for the mGGG model and the original GGG model. As a robustness analysis of the newly developed mGGG model, we also assessed another endpoint of salvage treatment-free survival. 


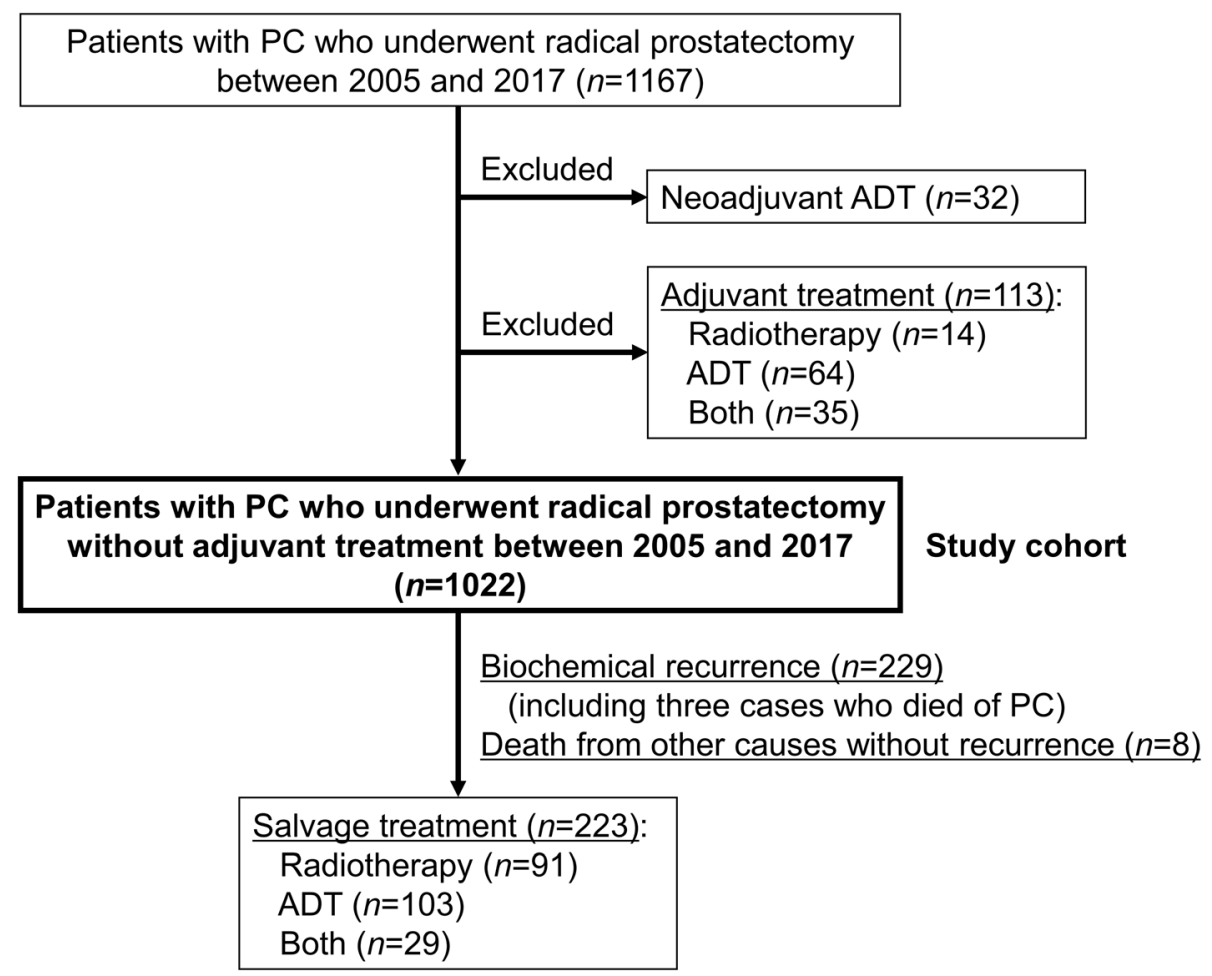

Fig. 1 Flow chart representing the study selection process

All statistical analyses were performed using JMP Pro version 14.0.0 and SAS version 9.4 (SAS Institute, Cary, NC, USA). $P<0.05$ was considered to indicate a significant difference.

\section{Results}

Patients' characteristics are shown in Table 1. Findings of extraprostatic extension and seminal vesicle invasion were included in pathological T stage as pT3a and pT3b, respectively. During a median follow-up of 45 (interquartile range: 21-77) months, 229 of 1022 (22.4\%) patients developed biochemical recurrence, and of them, three died of PC. Eight of 1022 (0.8\%) patients died from other causes without recurrence, resulting in 237 events for BRFS (Fig. 1).

The IQRS of each Gleason pattern was as follows: primary $5,1.81$ points (HR 6.13); secondary $5,1.37$ points (HR 3.92); tertiary 5, 0.87 points (HR 2.39); primary 4, 1.07 points (HR 2.91); secondary 4, 0.79 points (HR 2.21); and any Gleason pattern 3, 0 points (HR 1) (Table 2). On the basis of the IQRS, we developed the mGGG model, which classified patients into five groups (Table 3): I $(3+3$ or less); II $(3+4)$; III $(4+3)$; IV $(3+$ $4+\mathrm{t} 5,4+3+\mathrm{t} 5,3+5,5+3$, and $4+4) ; \mathrm{V}(4+4+\mathrm{t} 5$, $4+5,5+4$, and $5+5)$. There were significant differences in the survival profiles of the five groups of the mGGG model $(P<0.0001)$ (Fig. 2a), whereas the discrimination between group III and group IV of the original GGG model seemed insufficient (Fig. 2b). The mGGG model achieved a significantly higher predictive accuracy for BRFS (c-index: 0.672 ) than the original GGG model (cindex: 0.655$)(P=0.047)$. Univariate and multivariate Cox proportional hazards regression analyses for BRFS are shown in Table 4. Even after taking into account clinicopathological confounding factors in multivariate analysis, the mGGG model was predictive and prognostic in a score-dependent manner.

In the robustness analysis assessing salvage treatmentfree survival, significant differences were observed in the survival profiles of the five groups of the mGGG model $(P<0.0001)$ (Fig. 3a), whereas the discrimination between group III and group IV of the original GGG model seemed insufficient (Fig. 3b). Also for salvage treatment-free survival, the mGGG model achieved a significantly higher predictive accuracy (c-index: 0.638) than the original GGG model (c-index: 0.619$)(P=$ 0.029).

\section{Discussion}

To the best of our knowledge, the present study is the first quantification of the individual risk of each Gleason pattern, including tertiary Gleason pattern 5, after radical prostatectomy. Notably, the quantitative risk of tertiary $(<5 \%)$ Gleason pattern 5 was slightly higher than 
Table 1 Patient characteristics $(n=1022)$

\begin{tabular}{|c|c|}
\hline Parameter & Value \\
\hline Age at surgery, years, median (interquartile range) & $67(62-71)$ \\
\hline \multicolumn{2}{|l|}{ Surgical technique, no. (\%): } \\
\hline Open & $414(40.5)$ \\
\hline Laparoscopic & $32(3.1)$ \\
\hline Robotic & $576(56.4)$ \\
\hline Initial PSA, ng/ml, median (interquartile range) & $7.7(5.6-11.2)$ \\
\hline \multicolumn{2}{|l|}{ Pathological GS, no. (\%): } \\
\hline $3+3$ or less & 119 (11.6) \\
\hline $3+4$ & $395(38.7)$ \\
\hline $3+4+t 5$ & $53(5.2)$ \\
\hline $3+5$ & $17(1.7)$ \\
\hline $4+3$ & $148(14.5)$ \\
\hline $4+3+t 5$ & $94(9.2)$ \\
\hline $4+4$ & $59(5.8)$ \\
\hline $4+4+t 5$ & $8(0.8)$ \\
\hline $4+5$ & $108(10.6)$ \\
\hline $5+3$ & $2(0.2)$ \\
\hline $5+4$ & $19(1.9)$ \\
\hline $5+5$ & $0(0)$ \\
\hline \multicolumn{2}{|l|}{ Pathological T stage, no. (\%): } \\
\hline pT2 & $708(69.3)$ \\
\hline рT3a & $270(26.4)$ \\
\hline pT3b & $42(4.1)$ \\
\hline pT4 & $2(0.2)$ \\
\hline \multicolumn{2}{|l|}{ Pathological N stage, no. (\%): } \\
\hline $\mathrm{pNO} / \mathrm{x}$ & $1012(99.0)$ \\
\hline pN1 & $10(1.0)$ \\
\hline Resection margin, no. (\%) & $355(34.7)$ \\
\hline Median follow-up, months (interquartile range) & $45(21-77)$ \\
\hline
\end{tabular}

PSA Prostate-specific antigen, GS Gleason score

that of secondary $(5-50 \%)$ Gleason pattern 4 . Furthermore, our newly developed mGGG model more accurately predicted outcomes after radical prostatectomy than the original GGG model.

The pathological diagnostic system of $\mathrm{PC}$ is unique and complex in that it considers the worst and second worst lesions, as well as their percentages of areas $[1,3$, $18]$, whereas those of other cancers usually simply use the worst lesion. As described above, the Gleason scoring system, which was published in 1966 [1], has evolved over time. The concept of tertiary $(<5 \%)$ Gleason pattern 5 [2] has been implemented since 2005 [3] and the GGG [17] has been proposed since 2014 [18], although it does not incorporate the concept of tertiary Gleason pattern 5. Recently, a Japanese research group reported that integrating tertiary Gleason pattern 5 into GGG improved the prediction accuracy of biochemical recurrence after radical prostatectomy using a retrospective cohort of 1000 patients [16]. Similarly, Lucca et al. previously investigated the significance of tertiary Gleason pattern 5 in a large cohort $(n=4146)$ of patients with localized GS 7 PC treated by radical prostatectomy [13]. They identified the presence of tertiary Gleason pattern 5 as an independent predictor of biochemical recurrence and developed a prognostic model for 416 patients with GS $7(3+4$ or $4+3)$ and tertiary Gleason pattern 5 . This study judiciously highlighted the importance of tertiary Gleason pattern 5 among patients with GS 7, however, it did not evaluate the relative importance of tertiary Gleason pattern 5 in patients with all GS categories. Actually, no study so far has "quantified" the actual effect of tertiary Gleason pattern 5 on outcomes after radical prostatectomy. In this context, the present study clearly identified the IQRS of each Gleason pattern $(3 / 4 / 5)$ and its echelon (primary/secondary/tertiary) (Table 2). Notably, the IQRS of tertiary $(<5 \%)$ Gleason pattern 5 was slightly higher than that of secondary (5-50\%) Gleason pattern 4 . This finding is in accordance with previous reports, which emphasized the importance of (tertiary) Gleason pattern 5 in various settings of PC [4-16]. The present study confirmed the paramount importance of Gleason pattern 5, regardless of its amount, in predicting outcomes after surgery.

On the basis of the IQRS of each Gleason pattern, the present study developed the mGGG model, in which the original GGG model was used as a backbone with GS $3+4+\mathrm{t} 5$ (originally group II) and GS $4+3+\mathrm{t} 5$ (originally group II) shifted into group IV and with GS $4+4+$ t5 (originally group IV) shifted into group V (Table 3). Given that the mGGG model enables accurate

Table 2 The individual quantitative risk score (IQRS, points) and hazard ratio (HR) of each Gleason pattern (3/4/5) and its echelon (primary/secondary/tertiary)

\begin{tabular}{llll}
\hline & Pattern 5 & Pattern 4 & Pattern 3 or less \\
\hline Primary & 1.81 points (HR 6.13) & 1.07 points (HR 2.91) & 0 points (HR 1) \\
Secondary & 1.37 points (HR 3.92) & 0.79 points (HR 2.21) & 0 points (HR 1) \\
Tertiary & 0.87 points (HR 2.39) & & \\
\hline
\end{tabular}

HR is calculated from the IQRS by the following formula: $\mathrm{HR}=e^{\text {IQRS }}$ 
Table 3 The modified Gleason grade grouping (mGGG) model based on the individual quantitative risk score (IQRS, points) of each pathological Gleason score (GS)

\begin{tabular}{|c|c|c|c|c|}
\hline$\overline{m G G G}$ & Pathological GS (original GGG category) & $n$ & IQRS, points & $\mathrm{HR}$ \\
\hline $\mathrm{I}$ & $3+3$ or less (I) & 119 & 0 & 1 \\
\hline II & $3+4(I I)$ & 395 & 0.79 & 2.21 \\
\hline III & $4+3(I I I)$ & 148 & 1.07 & 2.91 \\
\hline \multirow[t]{5}{*}{ IV } & $3+4+t 5(I I)$ & 53 & 1.67 & 5.29 \\
\hline & $4+3+t 5(I I I)$ & 94 & 1.94 & 6.96 \\
\hline & $3+5(\mathrm{IV})$ & 17 & 1.37 & 3.92 \\
\hline & $5+3(\mathrm{IV})$ & 2 & 1.81 & 6.13 \\
\hline & $4+4(\mathrm{IV})$ & 59 & 1.86 & 6.45 \\
\hline \multirow[t]{4}{*}{ v } & $4+4+t 5(\mathrm{IV})$ & 8 & 2.73 & 15.40 \\
\hline & $4+5(V)$ & 108 & 2.44 & 11.43 \\
\hline & $5+4(V)$ & 19 & 2.61 & 13.57 \\
\hline & $5+5(V)$ & 0 & 3.18 & 24.06 \\
\hline
\end{tabular}

mGGG modified Gleason grade grouping, GS Gleason score, GGG Gleason grade grouping IQRS Individual quantitative risk score, HR Hazard ratio

prediction of BRFS after surgery with a higher cindex than the original GGG model, we deem that the mGGG model is a better scoring system than the original GGG. Additionally, the robustness of the mGGG model was confirmed by assessing salvage treatment-free survival, a treatment-oriented endpoint, other than BRFS, a pure oncological endpoint. Recently, the importance of treatment-oriented endpoints has been recognized in the field of oncology and some endpoints such as ADT-free survival have already been assessed in studies of PC [28]. Both for BRFS and salvage treatment-free survival, the predictive accuracy of the mGGG model was higher than that of the original GGG model. This might mean the usefulness of the mGGG model in the real-world clinical practice.

This study had several limitations. Firstly, it was a retrospective analysis of a single institution with a relatively short follow-up. Secondly, the pathological review of prostatectomy specimens was based on the 2005, but not 2014, ISUP Consensus Conference on Gleason Grading of Prostatic Carcinoma, although their criteria were generally identical except for some minor revisions. Thirdly, we could not assess GS $3+3$ with tertiary Gleason pattern 5 and GS $5+5$ because of lack of applicable cases. Given that the IQRS for GS $3+3+\mathrm{t} 5$ and GS $5+$ 5 are theoretically 0.87 points (HR 2.39 ) and 3.18 points (HR 24.06), respectively, GS $3+3+\mathrm{t} 5$ and $\mathrm{GS} 5+5$

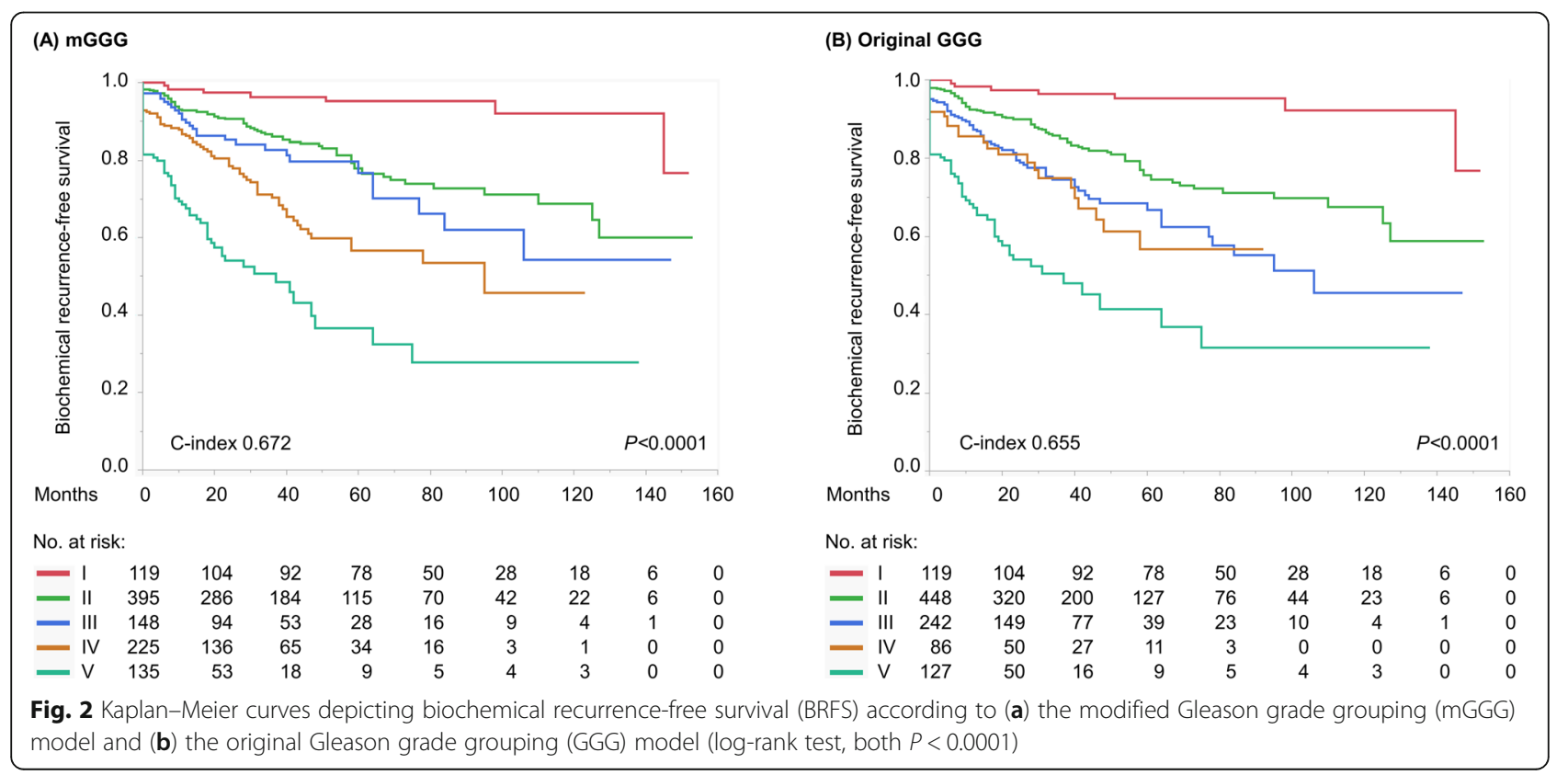


Table 4 Univariate and multivariate Cox proportional hazards regression analyses for biochemical recurrence-free survival (BRFS)

\begin{tabular}{|c|c|c|c|c|}
\hline \multirow[t]{2}{*}{ Variable } & \multicolumn{2}{|l|}{ Univariate regression } & \multicolumn{2}{|l|}{ Multivariate regression } \\
\hline & $\mathrm{HR}(95 \% \mathrm{Cl})$ & $P$ & $\mathrm{HR}(95 \% \mathrm{Cl})$ & $P$ \\
\hline Age at surgery (continuous) & 1.00 (0.98 to 1.02$)$ & 0.98 & 0.97 (0.95 to 0.99$)$ & $0.02^{*}$ \\
\hline Surgical technique: & & $<0.01^{*}$ & & $<0.01^{*}$ \\
\hline Open & Reference & - & Reference & - \\
\hline Laparoscopic & 0.49 (0.19 to 1.02$)$ & 0.06 & $0.72(0.28$ to 1.52$)$ & 0.42 \\
\hline Robotic & 0.64 (0.48 to 0.84$)$ & $<0.01^{*}$ & 0.59 (0.43 to 0.81$)$ & $<0.01^{*}$ \\
\hline Initial PSA: & & $<0.01^{*}$ & & 0.22 \\
\hline$<10 \mathrm{ng} / \mathrm{ml}$ & Reference & - & Reference & - \\
\hline $10-20 \mathrm{ng} / \mathrm{ml}$ & 1.54 (1.15 to 2.03$)$ & $<0.01^{*}$ & 1.25 (0.93 to 1.67$)$ & 0.13 \\
\hline$\geq 20 \mathrm{ng} / \mathrm{ml}$ & 2.76 (1.81 to 4.07$)$ & $<0.01^{*}$ & $1.30(0.84$ to 1.94$)$ & 0.23 \\
\hline mGGG model: & & $<0.01^{*}$ & & $<0.01^{*}$ \\
\hline । & Reference & - & Reference & - \\
\hline$\|$ & 4.53 (2.06 to 9.92 ) & $<0.01^{*}$ & 4.54 (2.07 to 9.96$)$ & $<0.01^{*}$ \\
\hline III & 5.93 (2.58 to 13.63$)$ & $<0.01^{*}$ & 5.79 (2.50 to 13.44$)$ & $<0.01^{*}$ \\
\hline IV & 10.22 (4.64 to 22.52) & $<0.01^{*}$ & 9.37 (4.20 to 20.86) & $<0.01^{*}$ \\
\hline V & 21.28 (9.61 to 47.09$)$ & $<0.01^{*}$ & 19.26 (8.50 to 43.66$)$ & $<0.01^{*}$ \\
\hline Pathological T stage: & & $<0.01^{*}$ & & $<0.01^{*}$ \\
\hline pT2 & Reference & - & Reference & - \\
\hline рТЗа & 2.85 (2.18 to 3.72 ) & $<0.01^{*}$ & 1.56 (1.17 to 2.09$)$ & $<0.01^{*}$ \\
\hline рT3b & 5.34 (3.12 to 8.60$)$ & $<0.01^{*}$ & 2.25 (1.25 to 3.85$)$ & $<0.01^{*}$ \\
\hline pT4 & 2.59 (0.15 to 11.75$)$ & 0.41 & 3.20 (0.18 to 15.60$)$ & 0.34 \\
\hline Pathological N stage: & & $<0.01^{*}$ & & $<0.01^{*}$ \\
\hline $\mathrm{pNO} / \mathrm{x}$ & Reference & - & & - \\
\hline $\mathrm{pN} 1$ & 11.88 (5.59 to 22.13) & $<0.01^{*}$ & $5.92(2.71$ to 11.49$)$ & $<0.01^{*}$ \\
\hline Resection margin & 3.48 (2.68 to 4.56$)$ & $<0.01^{*}$ & 2.25 (1.67 to 3.04 ) & $<0.01^{*}$ \\
\hline
\end{tabular}

HR Hazard ratio, $\mathrm{Cl}$ Confidence interval, PSA Prostate-specific antigen, $m G G G$ modified Gleason grade grouping *Statistically significant

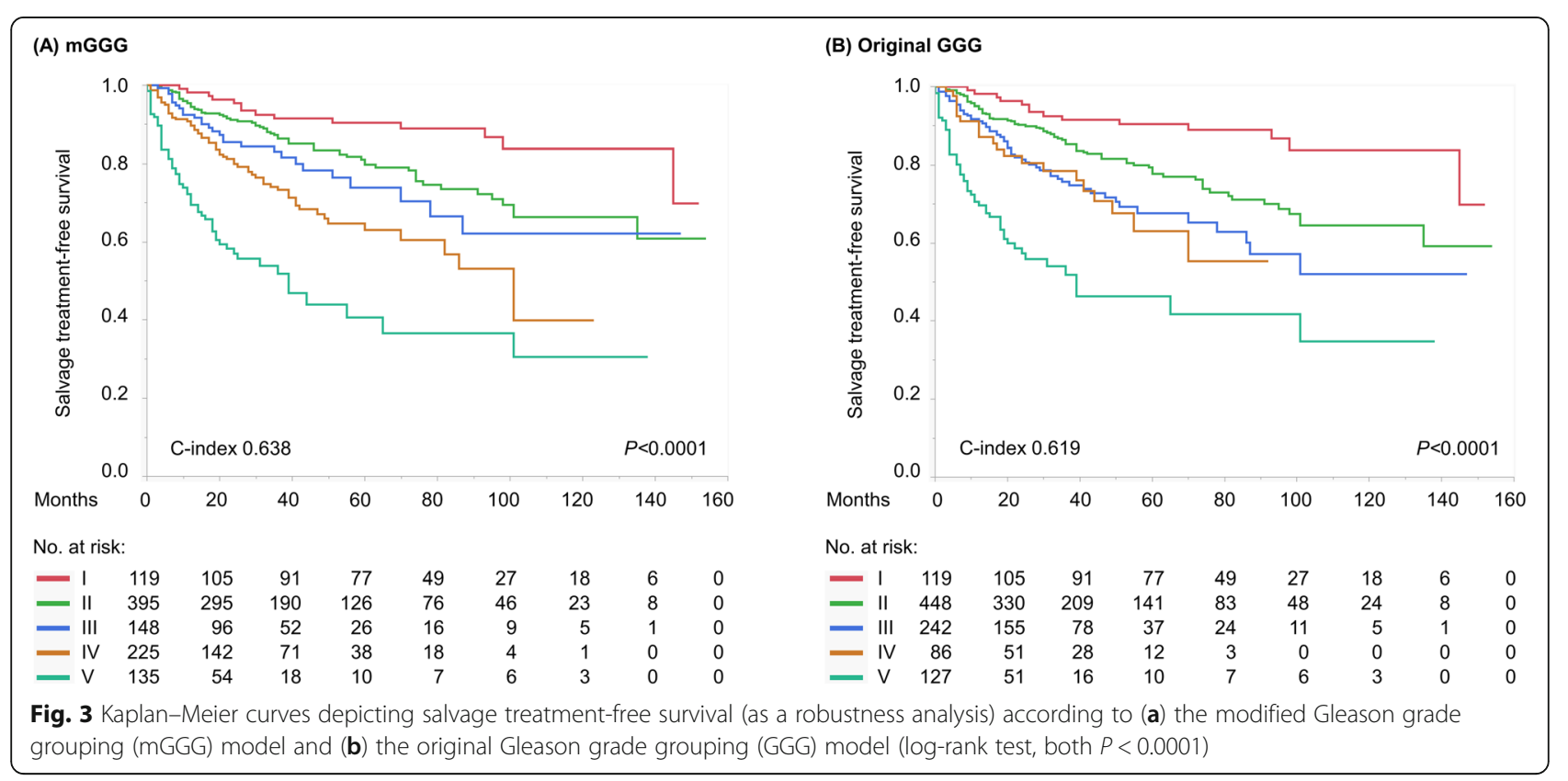


would be assigned to the mGGG category II and V, respectively. Further studies should be conducted to externally validate the mGGG model and to finally establish the optimal pathological diagnostic system of PC.

\section{Conclusions}

The quantitative risk of tertiary $(<5 \%)$ Gleason pattern 5 is slightly higher than that of secondary $(5-50 \%)$ Gleason pattern 4 . Our newly developed mGGG model more accurately predicts outcomes after radical prostatectomy than the original GGG model.

\section{Abbreviations}

ADT: Androgen deprivation therapy; GGG: Gleason grade grouping; GS: Gleason score; HR: Hazard ratio; IQRS: Individual quantitative risk score; ISUP: International Society of Urological Pathology; mGGG: Modified Gleason grade grouping; PC: Prostate cancer; PSA: Prostate-specific antigen

\section{Acknowledgments}

We thank Ellen Knapp, PhD, from Edanz Group (www.edanzediting.com/ac) for editing a draft of this manuscript.

\section{Authors' contributions}

ST contributed to the conception, study design, analysis, interpretation of data, and drafted the first manuscript. YU contributed to the analysis, interpretation of data, and drafted the first manuscript. TF, TM, AN, TK, and MS contributed to acquisition of data. HK and HF supervised the study, helped to draft the manuscript and were involved in revising it critically for important intellectual content. All authors read and approved the final manuscript.

\section{Funding}

None declared.

\section{Availability of data and materials}

Due to ethical restrictions, the raw data underlying this study are available from the corresponding author upon reasonable request.

\section{Ethics approval and consent to participate}

The present study was approved by the internal institutional review board of the Graduate School of Medicine and Faculty of Medicine, The University of Tokyo (approval number: 3124). Written informed consent was obtained from each patient prior to surgery. Patients were given the opportunity to decline participation in the study through the opt-out form on our website.

\section{Consent for publication}

Written informed consent was obtained from each patient prior to surgery. Patients were given the opportunity to decline inclusion in a publication of the study through the opt-out form on our website.

\section{Competing interests}

The authors declare that they have no competing interests.

\section{Author details}

${ }^{1}$ Department of Urology, Kyorin University School of Medicine, 6-20-2 Shinkawa, Mitaka, Tokyo 181-8611, Japan. ${ }^{2}$ Department of Urology, Graduate School of Medicine, The University of Tokyo, 7-3-1 Hongo, Bunkyo-ku, Tokyo 113-8655, Japan. ${ }^{3}$ Biostatistics Section, Department of Data Science, Center of Clinical Sciences, National Center for Global Health and Medicine, 1-21-1, Toyama, Shinjyuku-ku, Tokyo 162-8655, Japan. "Biostatistics Division, Central Coordinating Unit, Clinical Research Support Center, The University of Tokyo Hospital, 7-3-1 Hongo, Bunkyo-ku, Tokyo 113-8655, Japan. ${ }^{5}$ Department of Urology, Jichi Medical University, Yakushiji 3311-1, Shimotsuke, Tochigi 329-0498, Japan. ${ }^{6}$ Department of Pathology, Graduate School of Medicine, The University of Tokyo, 7-3-1 Hongo, Bunkyo-ku, Tokyo 113-8655, Japan.
Received: 10 February 2020 Accepted: 20 April 2020

Published online: 01 May 2020

\section{References}

1. Gleason DF. Classification of prostatic carcinomas. Cancer Chemother Rep. 1966;50:125-8.

2. Pan CC, Potter SR, Partin AW, Epstein Jl. The prognostic significance of tertiary Gleason patterns of higher grade in radical prostatectomy specimens: a proposal to modify the Gleason grading system. Am J Surg Pathol. 2000;24:563-9.

3. Epstein Jl, Allsbrook WC Jr, Amin MB, Egevad LL, ISUP Grading Committee. The 2005 International Society of Urological Pathology (ISUP) Consensus Conference on Gleason Grading of Prostatic Carcinoma. Am J Surg Pathol. 2005;29:1228-42.

4. Patel $\mathrm{AA}$, Chen $\mathrm{MH}$, Renshaw $\mathrm{AA}$, et al. PSA failure following definitive treatment of prostate cancer having biopsy Gleason score 7 with tertiary grade 5. JAMA. 2007;298:1533-8.

5. Sim HG, Telesca D, Culp SH, et al. Tertiary Gleason pattern 5 in Gleason 7 prostate cancer predicts pathological stage and biochemical recurrence. $J$ Urol. 2008;179:1775-9.

6. Trock BJ, Guo CC, Gonzalgo ML, et al. Tertiary Gleason patterns and biochemical recurrence after prostatectomy: proposal for a modified Gleason scoring system. J Urol. 2009;182:1364-70.

7. Nanda A, Chen MH, Renshaw AA, et al. Gleason pattern 5 prostate cancer: further stratification of patients with highrisk disease and implications for future randomized trials. Int J Radiat Oncol Biol Phys. 2009;74:1419-23.

8. Sabolch A, Feng FY, Daignault-Newton S, et al. Gleason pattern 5 is the greatest risk factor for clinical failure and death from prostate cancer after dose-escalated radiation therapy and hormonal ablation. Int I Radiat Oncol Biol Phys. 2011:81:e351-60.

9. Song C, Kim YS, Hong JH, et al. Treatment failure and clinical progression after salvage therapy in men with biochemical recurrence after radical prostatectomy: radiotherapy vs. androgen deprivation. BJU Int. 2010;106: $188-93$.

10. Hashine K, Yuasa A, Shinomori K, Shirato A, Ninomiya I, Teramoto N. Tertiary Gleason pattern 5 and oncological outcomes after radical prostatectomy. Jpn J Clin Oncol. 2011:41:571-6.

11. Jackson W, Hamstra DA, Johnson S, et al. Gleason pattern 5 is the strongest pathologic predictor of recurrence, metastasis, and prostate cancer-specific death in patients receiving salvage radiation therapy following radical prostatectomy. Cancer. 2013;119:3287-94.

12. Adam M, Hannah A, Budäus $L$, et al. A tertiary Gleason pattern in the prostatectomy specimen and its association with adverse outcome after radical prostatectomy. J Urol. 2014;192:97-101.

13. Lucca I, Shariat SF, Briganti A, et al. Validation of tertiary Gleason pattern 5 in Gleason score 7 prostate cancer as an independent predictor of biochemical recurrence and development of a prognostic model. Urol Oncol. 2015;33:71.e21-6.

14. Taguchi S, Shiraishi K, Fukuhara H, et al. Impact of Gleason pattern 5 including tertiary pattern 5 on outcomes of salvage treatment for biochemical recurrence in pT2-3NOMO prostate cancer. Int J Clin Oncol. 2016;21:975-80

15. Taguchi S, Shiraishi K, Fukuhara $\mathrm{H}$, et al. Optimal timing of salvage radiotherapy for biochemical recurrence after radical prostatectomy: is ultraearly salvage radiotherapy beneficial? Radiat Oncol. 2016;11:102.

16. Kato M, Hirakawa A, Kobayashi Y, et al. Integrating tertiary Gleason pattern 5 into the ISUP grading system improves prediction of biochemical recurrence in radical prostatectomy patients. Mod Pathol. 2019;32:122-7.

17. Pierorazio PM, Walsh PC, Partin AW, Epstein Jl. Prognostic Gleason grade grouping: data based on the modified Gleason scoring system. BJU Int. 2013;111:753-60.

18. Epstein JI, Egevad L, Amin MB, Delahunt B, Srigley JR, Humphrey PA, Grading Committee. The 2014 International Society of Urological Pathology (ISUP) Consensus Conference on Gleason Grading of Prostatic Carcinoma: Definition of Grading Patterns and Proposal for a New Grading System. Am J Surg Pathol. 2016;40:244-52.

19. Epstein Jl, Zelefsky MJ, Sjoberg DD, et al. A contemporary prostate Cancer grading system: a validated alternative to the Gleason score. Eur Urol. 2016; 69:428-35.

20. Spratt DE, Jackson WC, Abugharib A, et al. Independent validation of the prognostic capacity of the ISUP prostate cancer grade grouping system for 
radiation treated patients with long-term follow-up. Prostate Cancer Prostatic Dis. 2016;19:292-7.

21. Yeong J, Sultana R, Teo J, et al. Gleason grade grouping of prostate cancer is of prognostic value in Asian men. J Clin Pathol. 2017;70:745-53.

22. Hirao Y. Clinical practice guidelines for prostate Cancer: the Japanese Urological Association 2012 update. Tokyo: Kanehara-shuppan Press; 2012. (in Japanese).

23. Thompson IM, Valicenti RK, Albertsen $\mathrm{P}$, et al. Adjuvant and salvage radiotherapy after prostatectomy: AUA/ASTRO guideline. J Urol. 2013;190: $441-9$.

24. Mohler JL, Armstrong AJ, Bahnson RR, et al. Prostate Cancer, version 1.2016. J Natl Compr Cancer Netw. 2016;14:19-30.

25. Mottet N, Bellmunt J, Briers E, et al; members of the EAU - ESTRO - ESUR SIOG Prostate Cancer Guidelines Panel. EAU - ESTRO - ESUR - SIOG Guidelines on Prostate Cancer. Retrieved from: https://uroweb.org/ guideline/prostate-cancer/ Access date 30 June 2019.

26. Kweldam CF, Wildhagen MF, Bangma CH, van Leenders GJ. Disease-specific death and metastasis do not occur in patients with Gleason score $\leq 6$ at radical prostatectomy. BJU Int. 2015;116:230-5.

27. Anderson BB, Oberlin DT, Razmaria AA, et al. Extraprostatic extension is extremely rare for contemporary Gleason score 6 prostate Cancer. Eur Urol. 2017:72:455-60.

28. Decaestecker K, De Meerleer G, Lambert B, et al. Repeated stereotactic body radiotherapy for oligometastatic prostate cancer recurrence. Radiat Oncol. 2014;9:135.

\section{Publisher's Note}

Springer Nature remains neutral with regard to jurisdictional claims in published maps and institutional affiliations.

Ready to submit your research? Choose BMC and benefit from:

- fast, convenient online submission

- thorough peer review by experienced researchers in your field

- rapid publication on acceptance

- support for research data, including large and complex data types

- gold Open Access which fosters wider collaboration and increased citations

- maximum visibility for your research: over $100 \mathrm{M}$ website views per year

At $\mathrm{BMC}$, research is always in progress.

Learn more biomedcentral.com/submissions 